REVISTA

de la

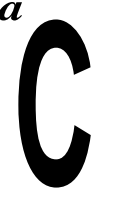

E

PAL

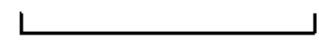

NUMERO 63

DICIEMBRE 1997

SANTIAGO DE CHILE

OSCAR ALTIMIR

Director

EUGENIO LAHERA

Secretario Técnico

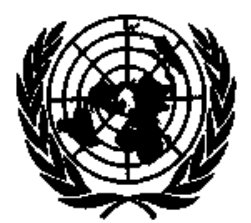

NACIONES UNIDAS 
El papel del sector público en el desarrollo latinoamericano

Ricardo Carciofi

La equidad en el presupuesto público

Juan Martin

Reformas a los sistemas de pensiones, mercado de capitales y ahorro

Andras Uthoff

Institucionalidad pública y políticas ambientales explícitas

e implícitas

Nicolo Gligo

La valoración de recursos naturales y ambientales no basada en el mercado en Centroamérica y el Caribe

Steve Shultz

Un modelo macroeconómico integrado para el Caribe

Lucio Vinhas de Souza

Virajes y derrapajes de la economía venezolana

José Miguel Benavente

¿Cuán no tradicionales son las exportaciones no tradicionales?

La experiencia de siete países de la Cuenca del Caribe

Alberto Gabriele

Apertura comercial y cambio estructural en la industria automotriz brasileña

Ruy de Quadros Carvalho, Sergio Robles Reis de Queiroz,

Flávia Luciane Consoni, loriara Costa y Janaína Pamplona da Costa

Historia evolutiva de una planta metalmecánica chilena

Jorge Katz y Héctor Vera

La importancia de la producción local y la pequeña empresa para el desarrollo de América Latina

Francisco Alburquerque

Publicaciones recientes de la CEPAL 


\section{La equidad en el presupuesto público}

\section{Juan Martin \\ Director de Programación del Sector Público, \\ Instituto Latinoamericano y del Caribe de \\ Planificación Económica y Social (ILPES)}

En este artículo se pretende hacer un recorrido por la realidad virtual del ámbito presupuestario y fiscal para identificar los posibles márgenes de libertad para lograr un mayor grado de convergencia entre el discurso político acerca de la equidad y el contenido real de las políticas públicas respecto de este objetivo. Con este propósito, se exploran posibles respuestas a cuatro interrogantes: qué significado se atribuye actualmente al concepto de equidad; cuáles son los espacios en el ámbito tributario para ampliar los recursos y mejorar la equidad vertical; cuáles son las vías para dar prelación al objetivo de equidad en la gestión del gasto público, y cómo podría asegurarse mayor consistencia dinámica entre crecimiento y equidad. Se concluye que es posible efectuar importantes avances en materia de equidad social en el ámbito fiscal, pero que para hacerlo se necesita una decisión política de primera magnitud apoyada por políticas públicas activas en un esfuerzo serio, sostenido y consistente. Para que esta decisión no sea meramente declarativa o clientelística, se la debe orientar al conjunto social, estableciendo explícitamente las prioridades del caso, y para evitar que se frustre, debe apoyarse en modalidades operacionales que combinen la participación social con un uso creativo y juicioso de los instrumentos de política pública. 


\section{I}

\section{Introducción}

El tema de la equidad en el presupuesto público es amplio y admite diversos enfoques. Como la prudencia aconseja acotarlo, el análisis se centrará aquí en los espacios de maniobra disponibles dentro del ámbito de las finanzas públicas para encarar avances en materia de equidad social.

Esta aproximación, aunque acotada, es significativa ya que la política fiscal -a través de sus componentes de ingresos, gastos y financiamiento- tiene importantes efectos sobre la equidad. Pero no debe soslayarse el hecho de que no basta la acción fiscal. Sin duda, el empleo bien remunerado constituye el medio más eficaz para promover una mayor equidad; a su vez, el volumen y la calidad del empleo tienen que ver con elementos propios de otros campos, además del fiscal. Todos estos factores fueron integrados por la CEPAL en su propuesta de transformación productiva con equidad (CEPAL, 1990 y 1992).

Para situar el análisis, conviene recordar que muchos de nosotros apreciamos el pasado inmediato de la región mediante dos conceptos sintéticos: uno, el de la década perdida, si el acento se coloca en los resultados socioeconómicos de los años ochenta en comparación con los de decenios anteriores y otro, el de los años del aprendizaje doloroso, si se hace hincapié en las lecciones aprendidas para encarar el futuro (Martin, 1994).

Ambas visiones de nuestro pasado inmediato son válidas, pero más importante todavía es que ellas son complementarias. Una nos señala los problemas pendientes, sujetos por supuesto a distinta ponderación según la realidad de cada país y el propio posicionamiento del observador. La otra, la del aprendizaje doloroso, sintetiza lo que hemos aprendido. Al respecto me parece pertinente destacar cuatro lecciones.

La primera es que son necesarios la interacción y el acomodamiento temporal entre las medidas de compensación social y los programas de inversión en capital humano. Las medidas compensatorias están orientadas a dar atención a necesidades que no son postergables y se engloban en el concepto de red social. Por su parte, la inversión en capital humano apunta a la recuperación del progreso social en la región para enfrentar mejor los desafíos que le impone el mundo contemporáneo.

La segunda es que el resultado de una década muy activa en materia de reformas tributarias ha sido una clara jerarquización — distinta a la del pasado- de los elementos que constituyen la trilogía de los tributaristas: eficiencia, simplicidad y equidad del sistema. El tema de la equidad no sólo ha perdido la preeminencia que tuvo en los años sesenta y setenta, sino que también ha experimentado un importante cambio de énfasis.

La tercera lección es que, en situaciones de límites fiscales severos, los conceptos de prioridad, sustitución y productividad del gasto público ganan mayor relevancia. Con frecuencia sabemos que gastamos mal y lo que es peor, a veces ni siquiera sabemos bien en qué gastamos.

La última es que el tema fiscal ha adquirido gran importancia para el logro y la preservación de los equilibrios macroeconómicos básicos, considerados hoy día como un objetivo intermedio indispensable para alcanzar un crecimiento sostenible. Esto a su vez nos conduce a la necesidad de articular los componentes de la política fiscal -ingresos, gastos y financiamiento públicos- y de coordinar mejor el manejo intertemporal de ellos.

Veremos ahora cómo utilizar estas cuatro lecciones para analizar la inequidad social que, si bien es un problema secular en la región, se ha agravado - y tal vez ha mutado de carácter- después de la década perdida. Nos ceñiremos a un conjunto de aspectos conceptuales que nos ayudarán a examinar las opciones y dilemas de política en torno al tema.

Una advertencia: nuestro punto de partida es la percepción de que la preocupación por la equidad es mayor en el discurso que en el contenido de las políticas públicas, de modo que nos proponemos hacer un recorrido en la "realidad virtual" del ámbito presupuestario y fiscal para identificar grados de libertad que permitan una mayor convergencia entre el discurso político y la realidad concreta. 


\section{II}

\section{Equidad: ¿un concepto único?}

La incipiente recuperación del crecimiento y la mejor situación fiscal en los primeros años noventa, junto con los visibles signos de asimetría en la distribución social de los costos del ajuste iniciado en los años ochenta, han vuelto a colocar sobre el tapete el tema de la equidad. El debate actual en torno a este tema se enardece por dos motivos vinculados con las expectativas de la gente, tanto en lo económico como en lo político. Por un lado, los importantes progresos logrados en el ámbito macroeconómico no han ido acompañados de progresos convincentes en la situación social. Por el otro, la dificultad de los gobiernos para articular propuestas suficientemente potentes frente a la magnitud del problema tornan poco fructífero el debate político necesario para avanzar en la materia.

$\mathrm{Si}$ bien la mayoría de las acciones fiscales tiene repercusiones en la equidad, el discurso gubernamental respecto de este tema privilegia las políticas públicas orientadas a los denominados sectores sociales. Así, comienza a perfilarse en la región un nuevo modelo de intervención pública en el campo social, cuyos instrumentos suelen agruparse bajo los títulos de privatización, focalización y descentralización. Los dos primeros configuran el núcleo de la estrategia: introducir hasta donde sea posible mecanismos de mercado para la provisión de servicios sociales, y limitar las prestaciones públicas directas a los grupos sociales más vulnerables a través de la focalización del gasto. La descentralización, como tercer componente del modelo, refuerza el movimiento hacia un mayor protagonismo de subgrupos sociales, en este caso las comunidades de base territorial, en los sistemas de prestación. Cabe hacer unos breves comentarios respecto de estos tres componentes.

\section{Descentralización}

Es muy probable que la descentralización traiga consigo significativas ganancias de eficiencia y un mayor control social sobre las prestaciones, a condición de que este proceso facilite la organización y participación ciudadanas y que los niveles subnacionales de gobierno se prueben abiertos a ellas. En cualquiera de los países de la región éste es un punto difícil de dilucidar de antemano.
Por otra parte, las responsabilidades transferidas desde el gobierno central a los gobiernos subnacionales deben guardar relación con los recursos financieros de que disponen. Por lo tanto, en la mayoría de los casos habrá que alcanzar algún tipo de acuerdo en materia de descentralización fiscal, congruente con la preservación de ese equilibrio. La experiencia regional reciente muestra serios desequilibrios en uno y otro sentido.

Por último, la simultánea descentralización hacia subgrupos sociales definidos por su pertenencia territorial y que necesariamente son heterogéneos entre sí, puede introducir inequidad entre jurisdicciones en cuanto a la cantidad y calidad de las prestaciones, debido a diferencias en la capacidad técnica y administrativa, la dotación de recursos, el potencial organizativo de la comunidad y la permeabilidad gubernamental a la participación ciudadana, entre otras.

Estas preocupaciones no pretenden configurar un argumento contrario a la descentralización, ya que ella constituye un importante medio para democratizar y hacer más eficiente la gestión pública. Pero sí abogan en contra de algunas visiones que la consideran como un fin en sí misma, o que adhieren a mecanismos espontáneos de propagación del movimiento descentralizador, diluyendo implícitamente las responsabilidades.

El cambio desde un sistema centralizado de prestaciones sociales a otro descentralizado requiere de una estrategia de transición, así como de regulación eficaz una vez alcanzado el nuevo régimen. De lo contrario, se pueden frustrar las expectativas en torno a su potencial o, peor aún, invalidar la descentralización como dirección correcta de cambio.

$\mathrm{Al}$ respecto, tal vez sea útil reconocer que la descentralización de hecho causa un reordenamiento de funciones en el conjunto del aparato estatal (Martin y Núñez del Prado, 1993). En consecuencia, no se trata solamente de fortalecer las capacidades técnicas e institucionales de las entidades hacia las cuales se descentraliza, sino también de redefinir y organizar las funciones de los órganos centrales y sectoriales para formular políticas de cobertura nacional, definir y vigilar el cumplimiento de normas, descubrir oportunamente desviaciones de importancia en la calidad de la 
gestión descentralizada respecto de los estándares nacionales y contar con los instrumentos necesarios para aplicar medidas correctivas de apoyo.

\section{Privatización y focalización}

Cabe ahora retomar el núcleo del nuevo modelo postulado para la intervención pública en los sectores sociales: la privatización y la focalización. Dicho modelo hace algunos aportes significativos en torno de estos dos componentes, sobre todo al sugerir una variedad de instrumentos poco utilizados hasta el presente.

Así, respecto de la privatización, junto con destacar las ventajas asignativas de los mercados, señala la importancia de introducir esquemas de recuperación total o parcial de costos, subsidiar la demanda, flexibilizar la oferta mediante la incorporación de prestadores privados, subcontratar el suministro de insumos e introducir incentivos para elevar la competitividad entre órganos públicos.

En cuanto a la focalización, el modelo hace un valioso llamado de atención sobre la pobreza, ya que ésta constituye la peor manifestación de la inequidad presente en una sociedad; subraya, en consecuencia, que debe darse prioridad a la lucha contra la pobreza, orientando varios programas sociales a la construcción de una red efectiva de seguridad social para la población con carencias extremas.

Los aportes en ambos casos suelen enmarcarse, sin embargo, en prescripciones implícitas de política cuya dificultad radica no tanto en sus propuestas parciales, sino en la frecuente omisión de algunas consideraciones. Destacaremos tres de ellas, a través de las preguntas siguientes.

¿El nuevo modelo de intervención pública asigna un papel subsidiario al Estado, o demanda políticas públicas activas orientadas al conjunto social? Particularmente en el ámbito de la política social no es útil oponer mercado e intervención pública, contrastando las virtudes de uno contra las falencias del otro; en este caso, especialmente, la experiencia revela tanto fallas de mercado como fallas del gobierno.

En realidad, lo importante es cómo aprovechar mejor la gran variedad de instrumentos disponibles para organizar novedosas modalidades mixtas de provisión de servicios sociales, con sistemas de incentivos apoyados en criterios de mercado y formas modernas de regulación pública (Carciofi y Beccaria, 1995). Además, conviene recordar que ni el mercado ni la intervención pública operan en un mundo abstracto, sino en uno complejo de instituciones concretas. En este mundo real la historia y la dinámica de los procesos cuentan y configuran un cuadro de condicionamientos recíprocos que obliga al arbitraje entre los objetivos de equidad y de eficiencia de la política social.

¿El combate a la pobreza es un objetivo prioritario, o es el único objetivo de la intervención pública en el campo social? El modelo tradicional de intervención pública en el campo social no otorgaba especial prioridad a la pobreza, sino que la consideraba más bien un caso extremo de la desigualdad distributiva en la que centraba su atención; el nuevo modelo, por el contrario, postula como prioridad absoluta de la acción pública el combate contra la pobreza. Ambas posturas son formas extremas de considerar la relación entre equidad y pobreza como fundamento para la necesidad de intervención pública. ${ }^{1}$

Desde el punto de vista tanto teórico como práctico, la intervención pública se justifica por consideraciones de equidad respecto del conjunto social y no sólo por la existencia de amplios grupos en situación de pobreza, aunque estos últimos sean acreedores de una atención preferente de la política social. Por los desafíos del desarrollo contemporáneo, también importa la acumulación de capital humano y para lograrla, es menester promover los talentos potenciales existentes en el conjunto de la sociedad, buscando eliminar la desigualdad de oportunidades y las discriminaciones en todo el espectro social.

¿Lo que importa es hacia quiénes se dirige el gasto social, o también cómo se comparte su financiamiento? La propuesta de focalizar el gasto público en los sectores más pobres de la sociedad considera dados el monto de los recursos disponibles y, sobre todo, los grupos sociales en que se genera su financiamiento. Sin embargo, la pregunta de quién paga la focalización es muy pertinente, tanto desde el punto de vista de quienes contribuyen efectivamente al financiamiento del gasto público, como de quienes son excluidos de los beneficios de la política social.

\footnotetext{
${ }^{1}$ La relación entre pobreza y equidad es evaluada según cuatro escuelas de pensamiento diferentes. Una es la que agrupa a quienes sólo están preocupados por la pobreza, sin consideración alguna de la desigualdad por encima de la línea de pobreza. La segunda reúne a quienes ponderan la reducción de la desigualdad como un objetivo de la política pública, pero dan prioridad a la eliminación de la pobreza mediante el ordenamiento de ambos objetivos. La tercera es la de aquellos que, preocupados por la equidad y la pobreza, están dispuestos a evaluar arbitrajes entre ambos objetivos. Finalmente, están quienes no le asignan un significado especial a la pobreza, sino que la consideran un componente del costo más amplio de la desigualdad (véase Atkinson, 1989).
} 
Por cierto, ambas dimensiones tienen importantes consecuencias sobre la equidad social en el sentido más amplio arriba mencionado. Como se verá en la sección siguiente, existen en la región — cuando se la compara con otras - holguras importantes para aumentar la carga tributaria y para distribuirla de manera más equitativa.

\section{III}

\section{Tributación y equidad: ¿se perdió la dimensión vertical?}

La década de 1980 fue muy prolífica en propuestas, reformas y experiencias tributarias; muchas de ellas emergieron de los países desarrollados, no sólo por los instrumentos utilizados, sino también por los objetivos que perseguían las reformas (Gómez, 1991).

\section{La orientación de la reforma}

Estos objetivos desplazaron el eje de la discusión desde la equidad del sistema tributario hacia el de su eficiencia, en el marco de una revalorización generalizada de los mecanismos de mercado y del papel del sistema de precios. En ese contexto se equipara el concepto de eficiencia con el de neutralidad: así, apuntar a un sistema tributario más eficiente es buscar un sistema más neutral, es decir, con mínima incidencia sobre las decisiones económicas.

Esto conlleva cambios sustanciales en los componentes básicos de cualquier impuesto: las tasas o alícuotas y la base imponible. En cuanto a las primeras, se tiende a importantes reducciones de las tasas marginales, pero buscando preservar las tasas medias, que determinan el nivel de la carga tributaria. La idea central es que esas tasas marginales son las que afectan el comportamiento de los agentes económicos, de modo que deben reducirse si se busca la neutralidad.

Respecto del segundo componente, la base imponible, se apunta a su ampliación y con ello se vincula el concepto de equidad horizontal: si dos individuos están en similar situación, deben pagar el mismo monto de impuesto. Este objetivo de equidad horizontal, que ha tendido a desplazar al anterior de equidad vertical, se logra en la medida en que las leyes tributarias traten a los iguales como tales. El resultado esperable es una ampliación de la base imponible. La reducción de las tasas marginales y la ampliación de la base se conjugan para sostener el nivel de tributación media necesario para financiar el gasto público.
Este movimiento hacia la eficiencia en el sistema tributario se aplica en todos los componentes de la estructura tributaria. En el impuesto al valor agregado, con'su generalización; en el impuesto a la renta, a través de la ampliación de la base imponible y la reducción de las tasas marginales; y en materia de impuestos a las importaciones, por la unificación de las alícuotas. Como todo el debate se encamina en una dirección similar, las recomendaciones de política tributaria que emanan de él son integradas y coherentes entre sí.

Ahora bien ¿por qué nos parecen importantes estas consideraciones? De modo general, por dos razones principales. La primera, porque de alguna manera ellas constituyen el anaquel de ideas en que se nutre el examen del tema en nuestros países, aunque con frecuencia se tergiversen sus contenidos o se los ubique fuera de contexto, omitiendo diferencias esenciales. La razón más importante, sin embargo, es otra, que está vinculada con los procesos de globalización y apertura. Para ilustrar la idea tal vez sea útil trazar una analogía con la frontera tecnológica internacional. En el caso tributario, los países de la región se encuentran al interior de dicha frontera, pero la globalización y la apertura empujan hacia ella y a la vez impiden transgredir sus principios fundamentales.

\section{Las reformas en América Latina}

Los años ochenta fueron también muy activos en reformas tributarias en la región (Carciofi, Cetrángolo y Barris, 1994). Tales reformas se inscribieron, sin embargo, en un escenario macroeconómico dominado por la dinámica del ajuste externo y los programas de estabilización interna, de modo que estuvieron orientadas principalmente a maximizar la recaudación tributaria para contribuir al logro de esos dos objetivos. No obstante, la carga tributaria real se mantuvo más o menos constante durante el período, debiendo 
los gobiernos recurrir a otros medios para cubrir el déficit fiscal.

En la mayoría de los casos, la reforma adoptó como eje la generalización del impuesto al valor agregado, con una o muy pocas tasas diferenciadas. El diseño de los sistemas de impuesto a la renta cambió radicalmente respecto del pasado, a través del desmantelamienlo de los incentivos basados en el gasto tributario, de mejores métodos para la indización de las bases imponibles y de la reducción de las tasas marginales y medias. En conjunto, los cambios apuntaron a simplificar el sistema para facilitar la administración tributaria y reducir la evasión y elusion, objetivos congruentes con la necesidad central de recuperar la capacidad de recaudación. Al respecto son dignos de destacarse los progresos realizados por algunos países de la región en este terreno.

El tema de la equidad vertical, objetivo central en décadas anteriores, no está en la agenda de las reformas recientes. Sobre la base de indicadores indirectos se puede conjeturar que, en el mejor de los casos, la incidencia fiscal no se hizo más progresiva o, más probablemente, aumentó su regresividad en el período.

La prescripción de política que hoy día prevalece en materia fiscal en la región reconoce la necesidad de introducir una mayor progresividad, pero también señala una forma particular de lograrla (Tanzi, 1992). En ella se da prioridad al objetivo recaudatorio de la política tributaria y a su neutralidad. Por otra parte, la tarea de conferir progresividad a la política fiscal se concentra en la reorientación del gasto público, por estimarse que la progresividad deriva de la incidencia neta sobre los distintos grupos sociales de las intervenciones gubernamentales en su conjunto, por el lado del ingreso y por el lado del gasto.

Esto no es convincente por dos razones. Una, la distancia que separa a los países de la región de aquella frontera internacional de realidades tributarias a que se hizo referencia. Otra, las enormes desigualdades que se observan en la región en cuanto a la distribución del ingreso y la riqueza. Ambas realidades concurren en la necesidad de hacer algo más respecto del objetivo de equidad vertical dentro del propio ámbito tributario.

Por cierto, esto exige revisar críticamente cómo se ha enfrentado en la región esta tarea en el pasado, y evitar la introducción de distorsiones y de conflictos con los otros objetivos de la política tributaria. La situación puede mejorar considerablemente si se utiliza un conjunto limitado de instrumentos que operen tanto sobre los impuestos indirectos como sobre los direc- tos y, sobre todo, si se otorga la prioridad del caso a un sólido desarrollo del sistema de administración tributaria. $^{2}$

Respecto de la tributación indirecta cabría examinar, en cada caso nacional, la propuesta de introducir una estructura simple pero no uniforme del impuesto al valor agregado acoplada con algunos impuestos específicos sobre determinados bienes (Carciofi y Cetrángolo, 1994). En este esquema, el impuesto al valor agregado proveería una base amplia de recaudación y los impuestos específicos permitirían una tributación diferenciada sobre un subconjunto de bienes cuyo consumo no fuese uniforme en los distintos estratos sociales.

Sin embargo, para avanzar en materia de equidad vertical es preciso actuar también sobre los muy bajos rendimientos de los impuestos directos; vale recordar aquí que la recaudación por este concepto es, para el promedio de los países de la región, inferior en diez puntos del PIB a la obtenida en los países de la Organización de Cooperación y Desarrollo Económicos (OCDE), descontadas las diferencias en los sistemas de seguridad social entre ambos grupos de países. ${ }^{3}$ Aunque hay espacios por ganar en los impuestos de base territorial, el peso de este deficiente desempeño recae en el impuesto a la renta.

En decenios pasados, la redistribución por vía tributaria estuvo centrada en refinamientos excesivos de este impuesto. Tal estrategia no funcionó por diversas razones: inflación alta y recurrente, debilidad del sistema de administración tributaria y persecución de demasiados objetivos con un mismo instrumento, entre otras. Sin embargo, un diseño simple del impuesto a la renta, siguiendo los patrones que prevalecen en los países desarrollados, junto con progresos sostenidos en

\footnotetext{
${ }^{2}$ La mejora del sistema de administración tributaria es esencial para reducir la elusión y evasión tributarias, sobre todo esta última, que alcanza cifras muy elevadas en casi todos los países de la región. De lo contrario, cargas tributarias relativamente bajas pueden generar una alta presión tributaria sobre quienes cumplen con sus obligaciones impositivas.

${ }_{3}^{3}$ En siete países de la OCDE, el promedio simple de la tributación directa como porcentaje del PIB es de $14 \%$, con un máximo de $24 \%$ (Suecia) y un mínimo de $8 \%$ (Francia). En trece países de América Latina, el promedio simple de la misma relación alcanza sólo a 3\%, con un máximo de 5\% (México) y un mínimo de 1\% (Bolivia). La diferencia entre ambos grupos de países, aunque importante, es mucho menor en las respectivas cargas tributarias totales, también como porcentaje del PIB: $27 \%$ de promedio simple en los países de la OCDE y $14 \%$ en los latinoamericanos. Este es un claro indicador del sesgo contrario de la tributación directa en América Latina (Véase CEPAL, 1992, cuadro IV-3).
} 
la administración tributaria, permitirían afrontar con éxito esta asignatura pendiente en la región.

Los avances potenciales en equidad que es posible obtener mediante la tributación no eximen, por supuesto, de la necesidad de mejorar considerablemente la asignación del gasto, tema que se abordará en la próxima sección. En realidad, ambas dimensiones se condicionan y legitiman mutuamente.

\section{IV}

\section{Equidad y gasto público: ¿cuánto espacio hay?}

Cuando se señala la necesidad de otorgar preeminencia al objetivo de equidad, las miradas convergen sobre el gasto público y por buenas razones. En este ámbito hay, en la mayoría de los países, importantes márgenes de maniobra vinculados con los conceptos de prioridad, sustitución y productividad del gasto. Para aprovechar estas holguras es necesario articular el objetivo de equidad con los otros objetivos de la política pública, y a la vez privilegiar el uso de los instrumentos de asignación de recursos establecidos institucionalmente.

La capacidad del gobierno para concretar objetivos depende de los recursos con que cuenta, pero también de los instrumentos de que dispone. Una de las áreas donde más puede acrecentarse la eficacia, la eficiencia y la racionalidad económica de la acción gubernamental es el sistema de programación, presupuesto y gestión de los recursos públicos. El punto focal de este sistema, por su vigencia legal e institucional, es el presupuesto público y éste bien vale una digresión.

Desafortunadamente, la dimensión fiscal de la crisis externa de los años ochenta llevó a un descalabro, mayor o menor según los países, de las capacidades institucionales para operar dicho sistema (Martin y Guijarro, comps., 1989). Los presupuestos públicos, en varios casos, pasaron a ser más un resultado que una tarea de programación. En algunas situaciones se produjo una pérdida casi total de la cultura presupuestaria y un resquebrajamiento de las relaciones institucionales, lo que se manifestó en varias dimensiones: entre las organismos globalizadores y los ejecutores del gasto; entre las autoridades económicas y monetarias, y entre los poderes ejecutivo y legislativo.

\section{Cambios en el sistema de administración fi- nanciera}

En los últimos años, varios gobiernos de la región han venido realizando ingentes esfuerzos para reconstruir y modernizar dicho sistema (Martin, 1992). En sus eta- pas iniciales, estas tareas se han orientado a resolver las deficiencias que se manifiestan en el corto plazo, a controlar la dimensión financiera del gasto y a recuperar la vigencia plena del ciclo presupuestario. El cumplimiento de estas etapas es sin duda esencial y en él se han alcanzado importantes logros en varios casos.

Uno de los aspectos novedosos de las reformas encaradas es la articulación entre las fases de formulación, ejecución y control presupuestario a través de nuevos sistemas integrados de administración financiera que abarcan las operaciones contables, de manejo del Tesoro y el crédito público, de personal y suministros, de presupuesto, y de seguimiento y control (ASIP/ ILPES, 1994). Estos nuevos sistemas, potenciados por los actuales medios computacionales, liberan a los funcionarios de asuntos rutinarios y les permiten dedicar su atención a cuestiones de naturaleza más analítica.

Cabe destacar asimismo la saludable tendencia a implantar clasificadores presupuestarios que permiten una gestión por objetivos, así como a elaborar indicadores y sistemas de seguimiento físico-económico de los distintos programas de gasto, en conjunción con controles de ejecución financiera relativamente más desarrollados.

La consolidación de esta tendencia ha de expandir su aplicación hacia los centros gestores, los que sobre la base de normas de carácter general y con el correspondiente apoyo técnico tienen una responsabilidad primaria en su desarrollo. Desde un punto de vista institucional la tarea no es menor: hay importantes inercias que vencer; es preciso delinear y establecer instancias de diálogo y coordinación y, sobre todo, lograr que la información - que no es precisamente un bien libre - fluya adecuadamente a través de la administración.

Además, es necesario mejorar la capacidad institucional para definir políticas sectoriales —en 
algunos casos también plurisectoriales- como marco para formular programas y proyectos técnicamente sólidos, ya que una buena asignación global de recursos tiene, como límite inferior, la calidad técnica de las propuestas de gasto.

Parece evidente que de no hacerlo, el presupuesto público difícilmente pueda ser otra cosa que un instrumento rígido, gobernado por la inercia y los compromisos burocráticos y políticos, sin fundamento real. Los ajustes hacia arriba o hacia abajo sólo pueden privilegiar un cierre financiero que afecta a todos por igual sin base en la prioridad o el mérito de los distintos programas de gasto, por la sencilla razón de que no se conocen lo suficiente.

En consecuencia, el desafío es de gran envergadura. La tarea alcanza a casi todos los organismos del sector público, pero principalmente a aquellos encargados de la política social. Las debilidades tradicionales - acentuadas por el impacto sobre el aparato estatal de la crisis de los años ochenta- se manifiestan en varios planos importantes. Entre otros, en la baja capacidad para formular orientaciones de política suficientemente fundadas y ajustadas a una restriccción presupuestaria, diseñar programas eficaces, sugerir acciones correctivas a partir de evaluaciones de las acciones en marcha y suministrar información oportuna y confiable.

\section{El presupuesto como instrumento de gestión gubernamental}

Cuando se intenta privilegiar la equidad, o por lo demás cualquier otro objetivo gubernamental, se requiere contar con un presupuesto en el que se puedan visualizar las oportunidades, ejercer las opciones y contar con alternativas reales de acción. La posibilidad de redirigir el gasto no siempre está limitada por los recursos; a veces la restricción está dada por la ausencia de buenos programas, o por fallas importantes en la capacidad de implementación de los centros gestores.

Un sistema en el que no se propicia tipo alguno de evaluación sustantiva y se desconocen los impactos de las acciones gubernamentales sobre la población a la que están dirigidas, ante filtraciones de varias clases lleva con seguridad a un bajo rendimiento de los importantes recursos actualmente asignados al campo social. En varios países esto preocupa cada vez más, al observarse que sólo una fracción reducida de cada unidad de cuenta asignada al gasto social llega a sus beneficiarios directos. Para enfrentar esta situación podrían adoptarse algunos procedimientos que ya se utilizan en países desarrollados, como son las evalua- ciones externas periódicas del desempeño de distintas áreas gubernamentales conducentes a revisiones presupuestarias.

Hasta aquí se ha discutido la relación entre presupuesto y equidad, privilegiando las cuestiones de naturaleza técnica. Esto no implica, por supuesto, desconocer que el proceso presupuestario también entraña una buena dosis de negociación política e institucional. Si bien es cierto que el proceso complejo mediante el cual se toman decisiones políticas no se puede reemplazar con meros cálculos técnicos, también debería ser claro que las necesarias decisiones políticas pueden adquirir mayor eficiencia y racionalidad global si se apoyan en una base técnica sólida y transparente.

Esta necesidad de transparencia debe ser resaltada cuando calificamos al presupuesto público. El presupuesto es uno de los principales instrumentos de acción del Ejecutivo, pero está sujeto a una revisión interactiva con el Parlamento, o sea con los representantes políticos de la ciudadanía; en ocasiones está también sometido a otras formas de revisión pública. Estos procesos por cierto no se benefician si el presupuesto es poco claro, su formato poco amigable y constituye un verdadero enigma que cuesta descifrar. Preguntas tan elementales como la de cuánto se va a destinar este año a educación no tienen respuesta inmediata, porque para obtenerla se debe transitar por una maraña de asignaciones presupuestarias. Esto conspira contra la posibilidad de convertir el presupuesto en una instancia para hacer explícitas las opciones, y lograr que las decisiones de gasto respalden los objetivos reales del gobierno y de las fuerzas políticas con representación parlamentaria.

Por último, cabe destacar que una reforma presupuestaria integrada al resto de los subsistemas de administración financiera del Estado, así como la introducción de una administración por objetivos, con programas bien diseñados, el desarrollo de sistemas para el seguimiento económico y financiero, la incorporación de mecanismos de evaluación de resultados y el ordenamiento según grandes políticas de gasto para aumentar la transparencia, son todas condiciones necesarias para mejorar el proceso presupuestario y ocupar así los espacios disponibles en el ámbito del gasto para introducir mayor equidad.

Lamentablemente estas condiciones necesarias no son suficientes. También se requiere insertar el debate presupuestario en un marco plurianual de proyecciones de ingresos y gastos, congruentes con la evolución macroeconómica y las políticas de desarrollo, temas que serán examinados en la última sección. 
V

\section{Crecimiento y equidad ¿cómo asegurar su consistencia dinámica?}

Los enfoques actuales para el tratamiento del desequilibrio fiscal ponen el acento en las modalidades de financiamiento del déficit público —en atención a sus distintas repercusiones macroeconómicas - y en la evolución de la deuda pública, reconociendo la necesidad de una política fiscal sustentable en el mediano y largo plazo.

\section{El entorno macroeconómico del presupuesto}

Cabe recordar que el presupuesto tiene dos componentes. Uno es de política fiscal, y que se expresa en una cierta combinación de agregados fiscales programada a partir de las metas macroeconómicas que el gobierno espera alcanzar con la ayuda de las finanzas públicas. El otro componente es de naturaleza coyuntural, ya que el presupuesto está sometido a influencias exógenas, hecho que en la etapa en que se formula se manifiesta en la adopción de supuestos y estimaciones relativos a acontecimientos relevantes que han de ocurrir en el año.

Una tarea central en la preparación del presupuesto es combinar ambos componentes de manera que las metas macroeconómicas y los supuestos y estimaciones sean consistentes entre sí. Esta consistencia debe surgir de la compatibilización entre los programas fiscal, monetario y cambiario, así como de la coherencia entre las proyecciones de gasto e ingreso de los distintos sectores institucionales.

Es normal que el desempeño efectivo de la economía y las variables exógenas que actúan sobre ella se aparten significativamente de los supuestos utilizados en la confección del presupuesto. En tal caso, el dilema que enfrenta el gobierno es si conviene reformular los componentes del presupuesto para asegurar el cumplimiento de las metas macroeconómicas iniciales, o bien ajustar éstas para tener en cuenta los problemas emergentes.

El ciclo presupuestario anual constituye una camisa de fuerza demasiado severa ante ese dilema. Por una parte, brinda escasa información acerca de la viabilidad y sustentabilidad de determinadas evoluciones de los agregados fiscales, y por otra, restringe el ejerci- cio de opciones de política que requieran delimitar sendas de acción en un horizonte de mediano plazo.

Por este motivo, la práctica gubernamental tiende cada vez más a inscribir el ejercicio presupuestario para el año en un marco plurianual que permita analizar la evolución proyectada de los agregados fiscales y sus repercusiones en el contexto macroeconómico. Esto, por cierto, no tiene como finalidad condicionar la actividad presupuestaria futura de manera rígida, sino contar con un instrumento flexible que permita plantear objetivos a mediano plazo y prestar especial atención a los requerimientos de una realidad económica cambiante y sólo parcialmente controlable por el gobierno.

En su dimensión microeconómica, el presupuesto presenta una asimetría fundamental en su composición. Mientras respecto de los ingresos contiene sólo una estimación basada en supuestos respecto del comportamiento de las bases tributarias y de los precios públicos durante el año, los gastos incluidos en él representan compromisos que, aun en los casos en que no estén respaldados por obligaciones legales, son difíciles de cambiar en el año. La adopción de un marco de programación plurianual apunta también a manejar esta asimetría fundamental.

Por el lado de los ingresos, el presupuesto permite discernir entre los efectos transitorios y los niveles más o menos permanentes de cada uno de sus componentes. El deterioro del presupuesto como instrumento de política fiscal no proviene de que los agregados fiscales ex post no coincidan con los presupuestados, lo que es normal puesto que los ingresos públicos dependen de bases y precios de evolución incierta. El verdadero problema se produce cuando factores transitorios llevan a decisiones que afectan aspectos permanentes del presupuesto de un modo que no guarda relación con las perspectivas y metas macroeconómicas de mediano plazo.

Por el lado de los gastos es bien sabido que en cualquier año presupuestario los gastos comprometidos en ejercicios anteriores alcanzan como mínimo un 70 u $80 \%$ de los ingresos corrientes. En consecuencia, el margen de maniobra para reasignar gastos en el ci- 
cío presupuestario anual es estrecho y, todavía peor, hacerlo puede ser costoso para la gestión pública. La adopción de un marco plurianual en este caso facilita el tránsito gradual de un programa de gastos a otro, en respuesta a cambios en las prioridades del gobierno.

En suma, la necesidad de producir información sobre el futuro que conlleva la definición de un marco plurianual favorece la unidad y coherencia intertemporal del proceso decisorio público. En particular, posibilita un manejo fiscal que apunte a dar solidez estructural a los ingresos públicos y a conferir flexibilidad al presupuesto de gastos, de manera que las necesidades de financiamiento del sector público sean compatibles con los recursos reales a su disposición.

De tal modo, su contribución puede ser decisiva para la gobernabilidad fiscal, entendida ésta como la capacidad del gobierno para llevar a cabo su política fiscal de modo que pueda sostenerse y sea creíble, y que tenga el mínimo costo posible para la eficacia de la gestión pública (Marcel, 1993). La razón no es exclusivamente técnica: producir información sobre el futuro busca transmitir a los actores involucrados en el proceso presupuestario los dilemas de la administración financiera pública. Esto puede contribuir significativamente a la generación de un clima favorable a la disciplina fiscal y también al logro de acuerdos políticos específicos para desarrollar una política fiscal sustentable, a través del control de la miopía impuesta por los factores coyunturales que operan sobre el presupuesto y los agregados fiscales.

Con estos antecedentes es posible construir una respuesta positiva a la pregunta planteada en el título de esta sección: la inserción del presupuesto en un marco plurianual de programación fiscal constituye un medio idóneo para hacer viable una evolución consistente del crecimiento y de la equidad, es decir facilita su consistencia dinámica.

\section{Crecimiento y distribución: un dilema de hie- rro}

Como es bien sabido, una economía en crecimiento posibilita mayores avances en materia de equidad social, sin que esto sea de manera alguna automático. Es más, en distintos países de la región ha habido períodos de crecimiento acompañados por un empeoramiento de la equidad social. La respuesta habitual a esta inconsistencia es que se requiere primero una fase de crecimiento sostenido para que, posteriormente, mejore la distribución. Esta aseveración se esgrime repetidamente como argumento ex ante y casi nunca se explica por qué tal consecuencia no se dio.

Por otra parte, también ha habido en la región experiencias de signo opuesto; es decir, políticas orientadas a producir efectos inmediatos en la dimensión distributiva que más temprano que tarde han desembocado en retrocesos de igual o mayor magnitud, inmersos en graves desequilibrios macroeconómicos y en un rápido agotamiento del crecimiento reactivador. ${ }^{4}$

En el primer caso, la estabilización y la recuperación del crecimiento que se logran no son suficientes para inducir un proceso de ahorro e inversión que haga viable el crecimiento sostenido; por otra parte, la pasividad con que se enfrenta el tema distributivo lo pospone siempre para una mejor ocasión. En el segundo, se toma ventaja de una coyuntura económico-financiera propicia para aplicar políticas no sustentables, excepto bajo la condición excepcional de una sucesión de buenas noticias que inexorablemente se interrumpe.

¿Cuáles son las posibles contribuciones de la política fiscal a la superación de este dilema de hierro en que parecen debatirse las economías de la región? La primera es la necesidad de adoptar políticas fiscales activas, tanto para el componente de ingresos como para el de gastos, y orientadas por una intervención pública en los sectores sociales, como se ha señalado en las secciones anteriores. La segunda es evitar que la política fiscal se transforme en una mera caja de resonancia del ciclo económico y de las perturbaciones externas. En ambos casos, el carácter plurianual del ejercicio presupuestario, apoyado por otros instrumentos disponibles (Martner, 1996), puede facilitar la acumulación no traumática de decisiones públicas al respecto, así como una mayor seguridad de que el conjunto de dichas acciones sea sustentable en el mediano y largo plazo.

\footnotetext{
${ }^{4}$ Existe la presunción de que el impuesto inflación tiene efectos distributivos regresivos. En el caso argentino, las estimaciones disponibles para el período 1980-1990 confirman dicha presunción: la carga media en el período soportada por el quintil más pobre $(8.6 \%$ de su ingreso) fue casi tres veces mayor que la que recayó sobre los individuos del quintil más rico (3.0\%). Véase Argentina, Ministerio de Economía y Obras y Servicios Públicos, 1992, cuadro 5, p. 14.
} 


\section{VI}

\section{Comentarios finales}

A modo de conclusión, cabe recordar las preguntas sobre las que se ha estructurado este trabajo, para luego presentar unos breves comentarios finales. Las preguntas han sido las siguientes: ¿Qué significado se le atribuye al concepto de equidad? ¿Hay espacios en el ámbito tributario para ampliar los recursos y mejorar la equidad vertical? ¿Cuáles son las vías para dar prioridad en la gestión del gasto público al objetivo de equidad? ¿Es posible que haya consistencia dinámica entre crecimiento y equidad?

Ahora entonces, los comentarios. Uno, la función redistributiva de la política fiscal debe compatibilizarse con las funciones asignativas y de estabilización, ya que interactúan significativamente, tanto en el ámbito de los ingresos como en el de los gastos públicos. Esto obliga a considerarlas simultáneamente.
Dos, es imprescindible recuperar un horizonte de mediano plazo en las finanzas públicas, pues así se introducen holguras fundamentales para acomodar las necesidades sociales y concatenar las acciones gubernamentales orientadas a satisfacerlas, con consideración expresa de su sustentabilidad.

Tres, dar prioridad al objetivo de equidad social es una decisión política de primera magnitud cuya materialización debe perseguirse activamente, a través de medidas específicas, en un esfuerzo serio, sostenido y coherente. Para que esta decisión no sea meramente declarativa o clientelística, se la debe orientar al conjunto social, estableciendo explícitamente las prioridades del caso. Y para evitar que se frustre, debe apoyarse en modalidades operacionales que combinen la participación social con un uso creativo y juicioso de los instrumentos de política pública.

\section{Bibliografía}

Argentina, Ministerio de Economía y Obras y Servicios Públicos (1992): Argentina en crecimiento, Buenos Aires.

ASIP/ILPES (Asociación Interamericana e Ibérica de Presupuesto Público/Instituto Latinoamericano y del Caribe de Planificación Económica y Social) (1994): Informe de relataría. Taller sobre sistemas integrados de administración financiera. LC/1P/R. 152, Santiago de Chile, ILPES/CEPAL. Consejo Regional de Planificación, 24 de noviembre.

Atkinson, A.B. (1989): Poverty, en J. Eatwell, M. Milgate y P. Newman, Social Economics. The New Palgrave, Londres, MacMillan Press.

Carciofi, R. y L.A. Beccaria (1995): Provisión y regulación pública en los sectores sociales: lecciones de la experiencia latinoamericana en la década del ochenta, Santafé de Bogotá, UNICEF Libros.

Carciofi, R. y O. Cetrángolo (1994): Tax Reforms and Equity in Latin America: A Review of the 1980's and Proposals for the 1990 's. Innocenti occasional papers. Economic policy series, $\mathrm{N}^{\circ} 39$, Florencia, Italia, Fondo de las Naciones Unidas para la Infancia (UNICEF), International Child Development Centre.

Carciofi, R., O. Cetrángolo y G. Barris (1994): Reformas tributarias en América Latina: análisis de experiencias durante la década de los años ochenta, Santiago de Chile, Comisión Económica para América Latina y el Caribe (CEPAL)/S.R.V. Impresos.

CEPAL (1990): Transformación productiva con equidad, LC/G 1601-P, Santiago de Chile. Publicación de las Naciones Unidas, $\mathrm{N}^{\circ}$ de venta S.90.II.G.6.
(1992): Equidad y transformación productiva: un enfoque integrado, LC/G.1701/Rev. 1-P, Santiago de Chile, agosto. Publicación de las Naciones Unidas, No. de venta S.92.II.G.5.

Gómez, J.C. (1991): Orientaciones en materia de reforma tributaria, Colección conferencias, Buenos Aires, Fundación Omega Seguros, diciembre.

Marcel, M. (1993): Gobernabilidad fiscal, presupuestos y finanzas públicas: un estudio a partir de la experiencia chilena, Washington, D.C. Banco Interamericano de Desarrollo (BID).

Martin, J. (1992): Los nuevos retos en la programación del sector público, LC/IP/L.052, Santiago de Chile, ILPES.

(1994): La política económica en la poscrisis y el proceso de reforma del Estado, LC/IP/R.150, Santiago de Chile, ILPES

Martin. J. y A. Núñez del Prado (1993): Gestión estratégica, planificación y presupuesto, Revista de la CEPAL $\mathrm{N}^{\circ} 49$, LC/G.1757-P, Santiago de Chile, CEPAL

Martin, J. y M. Guijarro (comps.) (1989): Introducción general de los compiladores, Finanzas públicas y desarrollo, Coloquio Franco-Latinoamericano, Buenos Aires, Grupo Editor Latinoamericano.

Manner, R. (1996): Indicadores de la política fiscal: diseño y aplicaciones para Chile, Revista de la CEPAL N ${ }^{\circ}$ 58. LC/G.1916-P, Santiago de Chile, CEPAL,

Tanzi, V. (1992): Fiscal policy and economic reconstruction in Latin America, World Development, vol. 20, $\mathrm{N}^{\circ}$ 5, Oxford, Reino Unido, Pergamon Press. 